\title{
Remote sensing data for assessing the equivalent water height (EWH) variety versus the level of forest disturbance in Central Siberia
}

\author{
Konstantin Krasnoshchekov ${ }^{1, *}$, Alexander Dergunov ${ }^{1}$, and Evgenii Ponomarev ${ }^{1,2}$ \\ ${ }^{1}$ Federal Research Center Krasnoyarsk Science Center of the SB RAS, Krasnoyarsk, Russia \\ ${ }^{2}$ Siberian Federal University, Krasnoyarsk, Russia
}

\begin{abstract}
The forests of the permafrost zone of Central Siberia are influenced by natural and anthropogenic factors. Using remote sensing data, disturbed areas of forest cover are detected in the IR range as an anomalies of the surface temperature, which are significant for a long time ( $\sim 20$ years). Long-term changes in the temperature balance of the surface affect both the state of the lower soil horizons and the dynamics of the seasonally thawed layer, and, therefore, can affect the variation in the water balance and groundwater runoff. For the area of interest, a trend is shown of $\sim 20 \%$ increase in the total area of disturbances per last two decades. A correlation analysis between large-scale thermal anomalies of the underlying surface and the series of gravimetric data on Equivalent Water Height $(\mathrm{EWH})$ parameter is performed for the territory of the two river basins of the Nizhnyaya Tunguska and Podkamennaya Tunguska (Central Siberia). As a first approximation we estimated the relationship between the forest and on-ground cover disturbance and thermal anomalies of the underlying surface, which affect the seasonal dynamics of groundwater.
\end{abstract}

\section{Introduction}

The forests of Central Siberia are subject to the complex impact of various anthropogenic, technogenic and natural factors. The development of the northern territories, logging activities, mining operations lead to an increase in the area of disturbed forest litter. At the same time, wildfires are remain one of the main factors of damage to vegetation, which account for up to $70 \%$ of the total number of fires in Eurasia [1].

Using remote sensing data, it was found that forest areas affected by various destructive factors, due to changes in spectral characteristics in a wide range of the spectrum, are confidently detected in the thermal IR range in the format of thermal anomalies of the underlying surface from satellites [2-4]. Such anomalies, as it was shown in a number of recent papers $[5,6]$, can cause changes in the stability of ecosystems in the region.

Also it has been shown [2, 6-9] that large-scale disturbances of vegetation and the anomalies of the temperature balance of the underlying surface (thermal anomalies) caused

\footnotetext{
* Corresponding author: krasko@icm.krasn.ru
} 
by wildfires affect the state of the permafrost layer, the level of groundwater and the dynamics of river flows. In order to verify this statement, we used a product of the GRACE satellite system, which provides gravimetric information expressed in terms of the equivalent water height $(\mathrm{EWH})$.

The purpose of this work is a geospatial analysis of the degree of destructive impact of natural and technogenic factors in the permafrost zone of Central Siberia. As well as, the assessment of the influence of surface thermal anomalies on the groundwater runoff within river basins of the study area.

The study area was the permafrost zone of Central Siberia $\left(56.8^{\circ}-68.3^{\circ} \mathrm{N}\right.$ and $87.2^{\circ}-$ $\left.114.9^{\circ} \mathrm{E}\right)$. We used data for the basins of two rivers: Nizhnyaya Tunguska with an area of $473,000 \mathrm{~km}^{2}$ and Podkamennaya Tunguska with an area of $240,000 \mathrm{~km}^{2}$. These basins are presented in a scale of the 4th level (of $12^{\text {th }}$ available) according to the classification Hydrological data and maps based on Shuttle Elevation Derivatives at multiple Scales (HydroSHEDS) (Fig. 1) [10].

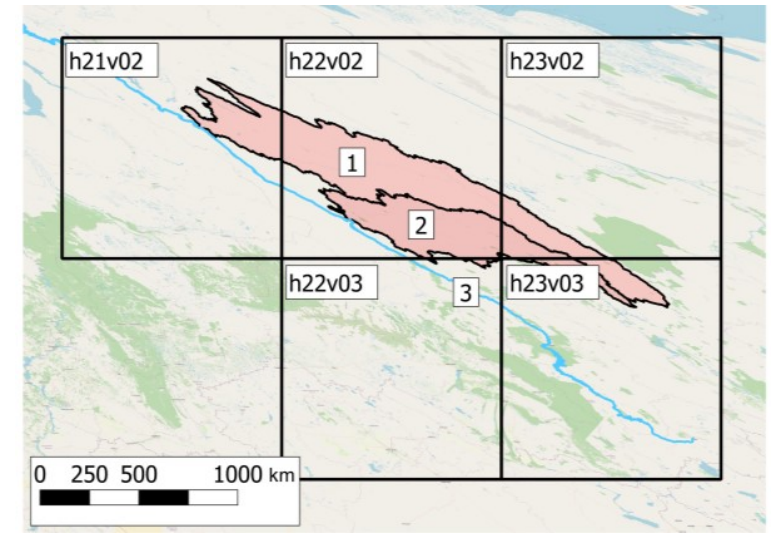

Fig. 1. Image of the study area and five MODIS grid cells in the WGS84 projection. Number 1 denotes the basin of the Nizhnyaya Tunguska river, number 2 - the basin of the Podkamennaya Tunguska river, number 3 - the Yenisei river.

For the study area, an archive of data on the average monthly surface temperature in the summer seasons (product MOD11B3) for the period from 2001 to 2019 and gravimetric data expressed by the EWH parameter for the period from 2013 to 2019 was formed.

\section{Materials and methods}

\subsection{Data of the temperature of the underlying surface}

To analyze the temperature of the underlying surface within the boundaries of the study area, the data of the IR range of the MODIS instrument installed on the Terra spacecraft were used. This is a MOD11B3 product, which is a daytime composite monthly average images using 20,22, 23, 29, 31 and 32 channels of the MODIS radiometer with a spatial resolution of $6 \mathrm{~km}$. The data was obtained from the LAADS DAAC resource (NASA) https://ladsweb.modaps.eosdis.nasa.gov/ [11].

The surface temperature maps of the study area were obtained on the MOD11B3 product within the boundaries of river basins (Fig. 2). The data sample consisted of 5 images corresponding to the following MODIS grid numbers: h21v02, h22v02, h23v02, h22v03, h23v03 (Fig. 1). 


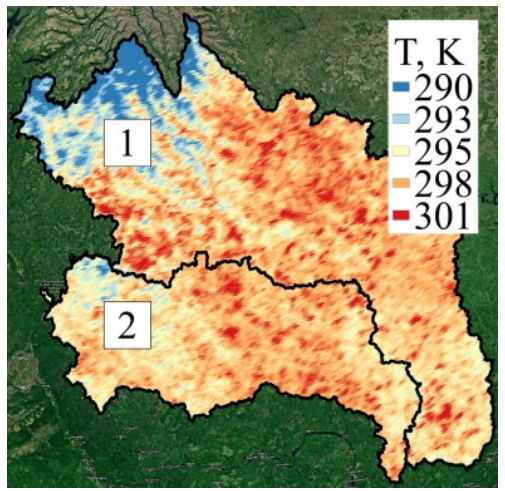

Fig. 2. Surface temperature distribution in the study area in July 2018. 1 - basin of the Nizhnyaya Tunguska river, 2 - basin of the Podkamennaya Tunguska river

For a detailed analysis of the dynamics of surface temperature, a polygonal GIS layer of smaller taxa was used, consisting of 18 river basins on a scale of 5 nesting levels out of 12 according to the HydroSHEDS classification (Fig. 3).

\subsection{Gravimetric data}

To assess the effect of thermal anomalies on the water cut of the study area, an archive of gravimetric data was formed based on information received from the GRACE and GRACEFO satellite systems. This data was obtained from the site https://podaac-tools.jpl.nasa.gov/. They are provided with aggregation by month, contain information about the height of the water layer above the geoid and are expressed as the EWH (Equivalent Water Height) parameter. The data has a spatial resolution of $1 \times 1$ degree. The data archive contains information from January 2013 to December 2019.

\section{Results and discussion}

Figure 3 shows the results of classification, which reflect the degree of disturbance $(\gamma)$ of smaller river basin within the basins of the Nizhnyaya Tunguska river and Podkamennaya Tunguska river for 2001, 2009, and 2019.

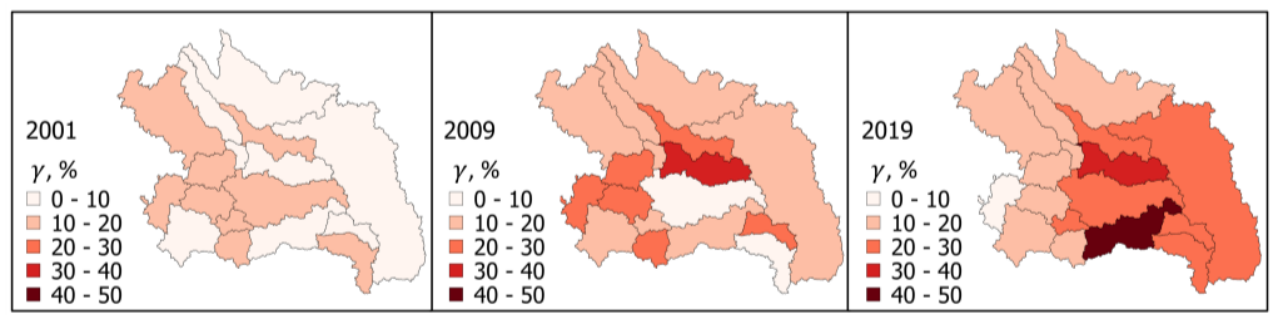

Fig. 3. The degree of disturbance $(\gamma)$ of the study area in 2001, 2009 and 2019

Based on the analysis of the values of the underlying surface temperature, it was found that from 2001 to 2009 the total area of disturbances increased by $7.77 \%$ or $36752.1 \mathrm{~km}^{2}$ within the basin of the Nizhnyaya Tunguska river. At the same time the total level of 
disturbances within the basin of the Podkamennaya Tunguska river increased by $4.7 \%$ or $11,280 \mathrm{~km}^{2}$. During the next period of 2009-2019 this characteristics increased by $10.34 \%$ or $48908.2 \mathrm{~km}^{2}$ and by $17.19 \%$, or $41,256 \mathrm{~km}^{2}$, respectively. The total percentage of areas characterized with signs of disturbed vegetation cover was $9.36 \%$ or $66,736.8 \mathrm{~km}^{2}$ (in 2001), $16.09 \%$ or $114,721.7 \mathrm{~km}^{2}$ (in 2009) and $28.8 \%$ or $205344 \mathrm{~km}^{2}$ (in 2019) (Fig. 4).

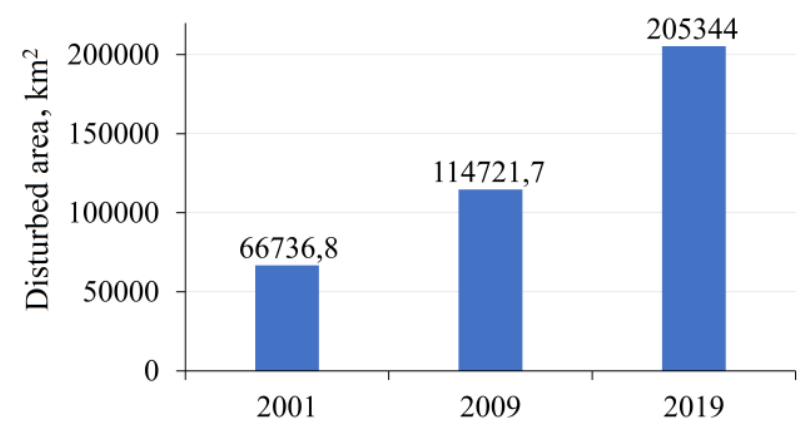

Fig. 4. Changes in the areas of disturbance of the underlying surface of the study area during two 10year periods.

Wildfires make the greatest contribution to the appearance of disturbance of the underlying surface. This applies to all 18 surveyed polygons (which are the basins of smaller rivers, see fig. 3). Also, an anthropogenic factor cannot be excluded, namely logging activities, mining, etc.

In order to determine whether the degree of disturbance of the forest cover has a relationship with the water cut in the study area, the variance values for the temperature of the underlying surface and the EWH parameter for the study area were calculated. The overall average surface temperature and EWH parameter were also calculated for the territory of the two studied river basins.

Table. Statistical parameters of EWH and temperature data for the territory of two basins with aggregation by season

\begin{tabular}{|c||c||c|c||c||c|}
\hline \multicolumn{1}{|c||}{\multirow{2}{*}{ Season }} & \multirow{2}{*}{ Year } & \multicolumn{2}{c||}{ GRACE EWH, cm } & \multicolumn{2}{c|}{ MODIS t, K } \\
\cline { 3 - 6 } & & $\boldsymbol{\sigma}$ & $\mathbf{M}$ & $\boldsymbol{\sigma}$ & $\mathbf{M}$ \\
\hline \hline \multirow{2}{*}{ Winter } & \multirow{3}{*}{2013} & 0,017 & $-0,026$ & 3,0 & 242,1 \\
Spring & 0,031 & 0,025 & 3,2 & 274,7 \\
Summer & & 0,022 & $-0,065$ & 2,3 & 294,6 \\
Autumn & & 0,011 & $-0,041$ & 3,5 & 257,4 \\
\hline Winter & & 0,017 & 0,051 & 4,8 & 241,3 \\
Spring & \multirow{3}{*}{2014} & 0,033 & 0,106 & 4,0 & 269,3 \\
Summer & & 0,029 & $-0,008$ & 1,9 & 293,1 \\
Autumn & & 0,021 & $-0,037$ & 4,4 & 262,2 \\
\hline Winter & & 0,032 & 0,067 & 5,1 & 245,6 \\
Spring & \multirow{2}{*}{2015} & 0,031 & 0,125 & 3,0 & 268,9 \\
Summer & & 0,029 & $-0,067$ & 1,9 & 291,7 \\
Autumn & & 0,019 & $-0,054$ & 2,3 & 282,2 \\
\hline
\end{tabular}




\begin{tabular}{|c||c||c|c||c|c|} 
Winter & & 0,027 & 0,021 & 3,0 & 247,6 \\
Spring & \multirow{2}{*}{2016} & 0,025 & 0,055 & 3,5 & 267,3 \\
Summer & & 0,034 & $-0,071$ & 1,8 & 294,2 \\
Autumn & & 0,015 & $-0,089$ & 2,7 & 248,0 \\
\hline Winter & \multirow{2}{*}{2017} & 0,032 & $-0,044$ & 4,1 & 240,9 \\
Spring & & 0,028 & 0,035 & 4,2 & 269,5 \\
Summer & & 0,016 & 0,027 & 3,4 & 294,8 \\
\hline Summer & 2018 & 0,033 & $-0,051$ & 2,4 & 296,5 \\
\hline Winter & & 0,022 & 0,003 & 2,9 & 242,9 \\
Spring & \multirow{2}{*}{2019} & 0,025 & 0,037 & 4,0 & 268,7 \\
Summer & & 0,026 & $-0,036$ & 2,2 & 294,8 \\
Autumn & & 0,020 & $-0,072$ & 3,5 & 264,4 \\
\hline
\end{tabular}

It can be seen from the table that some time intervals are missing, for example, autumn 2017 and the whole of 2018, with the exception of the summer period. This is due to the lack of data from the GRACE system due to its unstable operation.

The table shows that the maximum values of the EWH parameter correspond to the spring period, the minimum values of this parameter are observed in the autumn period. In order to find out that an increase in the temperature of the underlying surface affects the state of the permafrost layer, the level of groundwater and the dynamics of river flows, it is necessary to compare the series of data on the temperature of the underlying surface with the series of data on the EWH parameter.

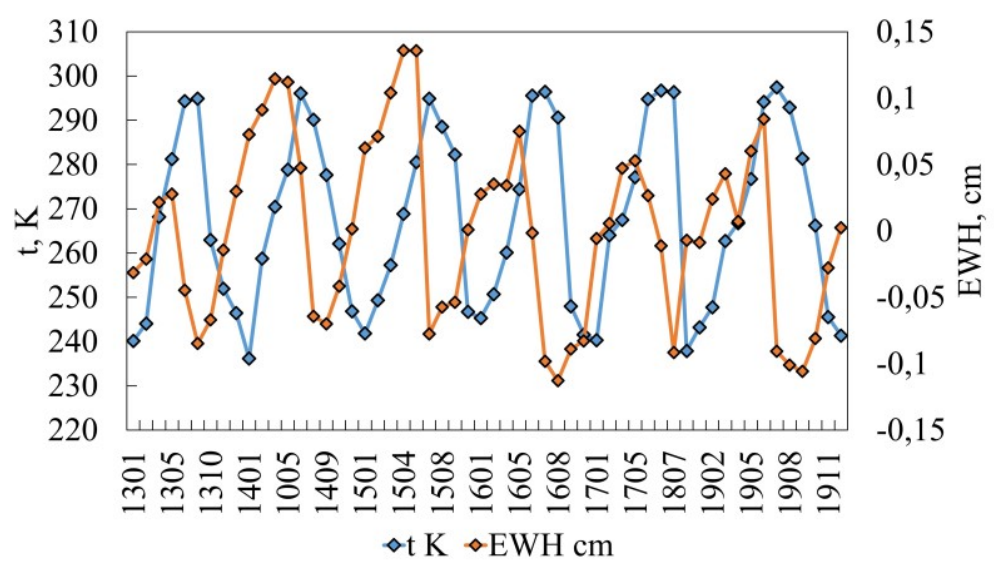

Fig. 5. Annual temperature fluctuations ( $\mathrm{t}$ ) and EWH

Figure 5 shows the monthly average values of the EWH parameter and surface temperature for the territory of two river basins in the period from January 2013 to December 2019. These surface temperatures have a positive trend, which is consistent with the results presented above. The negative trend in the values of the EWH parameter for the period under study indicates a decrease in the total water cut of the territories of the two river basins. In combination with a positive temperature trend, it can be assumed that there is a relationship between an increase in the temperature of the underlying surface due to an increase in the number and areas of disturbed forest areas and a negative EWH trend, which 
indicates a decrease in groundwater reserves in the study area. To check the relationship between the runoff data from the Podkamennaya Tunguska river and the GRACE and GRACE-FO gravimetric measurements for the territory of the corresponding river basin, we compared the values of the EWH parameter over the study area and the river runoff values. The graph of the correlation field (Fig. 6) demonstrates the general relationships between the parameters of "river runoff" - "EWH parameter".

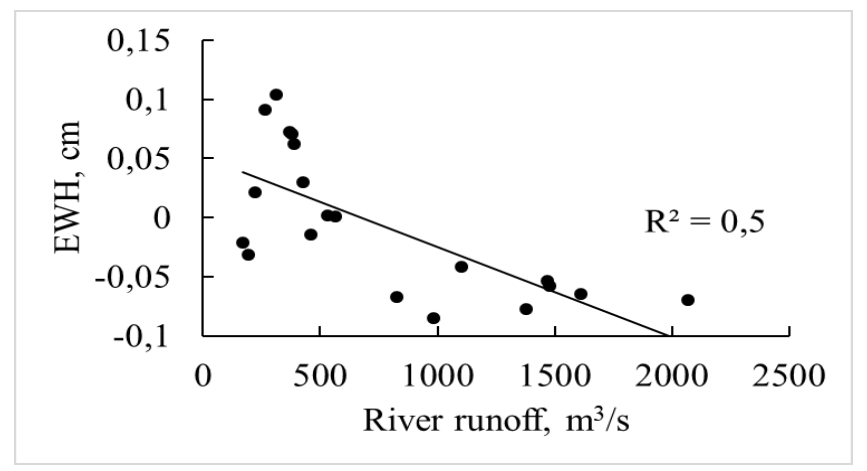

Fig. 6. Correlation field of the river runoff rate of the Podkamennaya Tunguska river and the EWH parameter

Figure 6 shows that the peak values of the river runoff correlate with the maximum value of the EWH parameter. The in phase of the minima of both investigated parameters was also confirmed.

\section{Conclusions}

The remote sensing data in the IR range makes it possible to assess the degree of disturbance of territories by analyzing the surface temperature and comparing the detected temperature anomalies at the sites of damaged vegetation with the background values of the underlying surface temperature. As studies show, thermal anomalies are significant even after $10-15$ years $[2,6]$ of recovery processes, which makes monitoring the state of forest cover using satellite data in the infrared range promising.

According to the results of calculations in the study area, there is an increasing trend in the areas of disturbances of the underlying surface over the past 20 years. In 2001, the total area of disturbance was $66736.8 \mathrm{~km}^{2}$, and it was rising up to $114,721.7 \mathrm{~km}^{2}$ in 2009 and up to $205344 \mathrm{~km}^{2}$ in 2019 .

Wildfires make the greatest contribution to the appearance of disturbance of forests and on-ground cover of the region. A technogenic factor, for example, logging activities, mining, etc., also directly affects the distribution of thermal anomalies, which are confidently detected by using of remote sensing data in the thermal IR range.

The combined use of gravimetric data and data on the temperature of the underlying surface allows, in a first approximation, to substantiate the applicability of gravimetric survey data for analyzing the dynamics of river runoff changing under conditions of largescale post-fire damage to the larch forests in the permafrost zone.

\section{Acknowledgments}

This research was funded by the Russian Foundation for Basic Research (RFBR) and Government of the Krasnoyarsk krai, and Krasnoyarsk krai Foundation for Research and 
Development Support, grant number 18-41-242003 "Modeling and satellite monitoring of effects from thermal anomalies of the underlying surface in the seasonally thawed soil layer of the permafrost zone of Siberia", and grant number 20-44-242002 "Instrumental monitoring of physical properties and numerical modeling of the state of technogenically disturbed soils in Siberia", and Grant of the East Siberian Oil and Gas Company aimed at supporting scientific research of applied importance in 2020.

\section{References}

1. E.A. Loupian, S.A. Bartalev, I.V. Balashov, V.A. Egorov, D.V. Ershov, D.A. Kobets, K.S. Senko, F.V. Stytsenko, I.G. Sychugov, Sovr. Probl. DZZ Kosm 6, 158 (2017)

2. E.I. Ponomarev, T.V. Ponomareva, Cont. prob. of ecol., 4, 420 (2018)

3. K.V. Krasnoshchekov, A.V. Dergunov, E.I. Ponomarev, Sovr. Probl. DZZ Kosm 2, 87 (2019)

4. N.D. Yakimov, E.I. Ponomarev, E3S Web of Conferences 149, 03008 (2020)

5. A.A. Knorre, AV. Kirdyanov, A.S. Prokushkin, P.J. Krusic, U. Büntgence, Sci. Total Environ 652, 314 (2019)

6. E.I. Ponomarev, O.V. Masyagina, K.Y. Litvintsev, T.V. Ponomareva, E.G. Shvetsov, K.A. Finnikov, Forests 11, 8, 790 (2020)

7. E.I. Ponomarev, T.V. Ponomareva, A.S. Prokushkin, Water. 11, 6, 1146 (2019)

8. M. Helbig, J.M. Waddington, P. Alekseychiket [et al.], Nat. Clim. Change 10555 (2020)

9. S. T. Im, V. I.Kharuk, Izvest., Atm. and Oc. Phys. 51, 8 (2015)

10. B. Lehner, G. Grill, Hydrol. Process 27 15. 2171 (2013)

11. Z. Wan, S. Hook, G. Hulley, MODIS land surface temperature products users' guide, ICESS (2015). 